\title{
PROTEINOGRAMA DO LIQUIDO CEFALORRAQUEANO NA NEUROPATIA DIABÉTICA
}

\author{
A. Spina-França * \\ Horacio M. Canelas **
}

Madonick e Margolis 10 analisaram o comportamento da concentração protêica do líquido cefalorraqueano (LCR) em 100 pacientes diabéticos. Verificaram que não há dependência entre proteinorraquia e glicemia ou proteinemia. O aumento da proteinorraquia foi observado apenas nos casos mais graves de diabetes mellitus, acompanhados de acometimento do sistema nervoso.

Entre as complicações do diabetes mellitus, a neuropatia diabética (ND) é a que se acompanha de hiperproteinorraquia com maior freqüência ${ }^{11}$. Embora o aumento da concentração protêica seja comum na ND, não costuma atingir cifras elevadas; Rundles ${ }^{14}$ refere que estas são encontradas ocasionalmente.

A natureza e a origem da hiperproteinorraquia encontrada na ND são problemas ainda incompletamente resolvidos. Neste trabalho são analisados os dados referentes ao proteinograma do LCR de uma série de pacientes corn ND, no sentido de contribuir para o estudo dêsse problema.

\section{MATERIAL E MÉTODOS}

Foi estudado o proteinograma do LCR de 22 pacientes com neuropatia diabética.

Os pacientes foram acompanhados na Unidade de Diabetes da $1^{\text {a }}$ Clínica Médica da Faculdade de Medicina da Universidade de São Paulo. Para cada caso foi analisado o proteinograma de uma amostra de LCR lombar. Em 17 dêles foi também analisado na ocasião o proteinograma do sôro sangüineo (sôro). Parte da amostra de LCR estudada foi submetida a exame citológico e a exame imunológico (reações de fixação do complemento para sífilis e para cisticercose).

$O$ exame citológico do LCR foi realizado e interpretado segundo a padronização adotada em nosso meio ${ }^{9}$. As reaçōes imunológicas foram feitas segundo a técnica de Kolmer ${ }^{7}$. A concentração protêica total do LCR foi determinada pelo método turbidimétrico do ácido tricloracético ${ }^{1} \overline{\mathrm{e}}$ a do sangue pelo do biureto ${ }^{\top}$. $\mathrm{O}$ estudo das frações protêicas do LCR e do sôro foi feito pela eletroforese em papel, segundo

Trabalho da Clínica Neurológica (Prof. Adherbal P. M. Tolosa) da Faculdade de Medicina da Universidade de Sāo Paulo: *Assistente-doutor; ** Professor-assistente. 


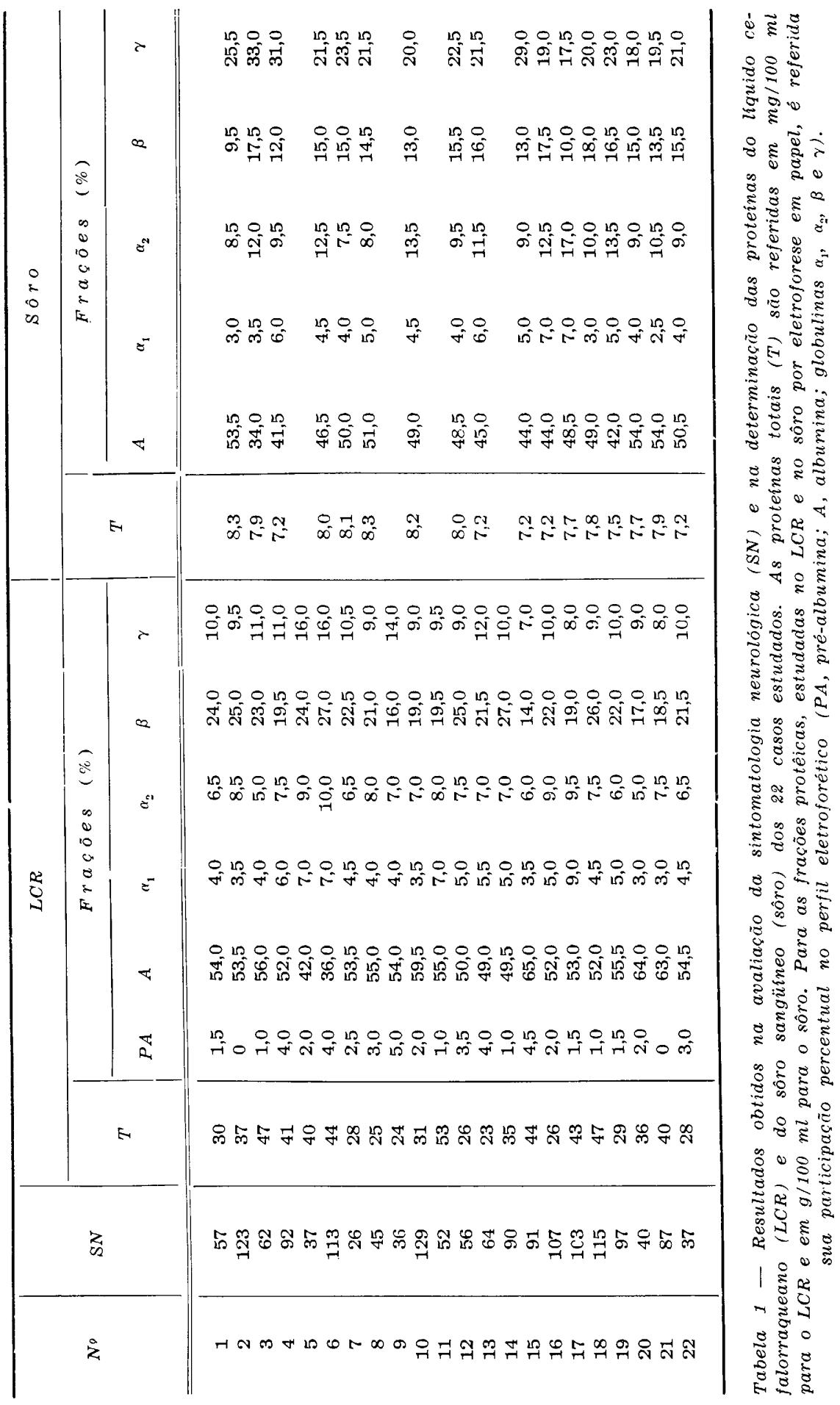


técnica descrita $1 \%$, e os resultados obtidos foram interpretados segundo os padrões normais estabelecidos para essa técnica ${ }^{16}$.

A sintomatologia neurológica foi avaliada de modo semiquantitativo, segundo tabela proposta por Alexander ${ }^{1}$ e modificada por Canelas e col.5. A sensibilidade vibratória (frequente e precocemente alterada na neuropatia diabética ${ }^{4}$ ) foi medida com palestesiômetro eletromagnético*; os valôres obtidos (em volts) foram submetidos às conversões logarítmica e etária propostas por Mirsky e col. 1n, sentio o indice de hipopalestesia referido pela elevação da soma dos limiares nos anulares e háluces 2 , multiplicada pelo fator de uniformizaçāo 10 . Os cômputos totais de cada paciente foram correlacionados com as concentraçōes de cada fração protêica do LCR e com o total respectivo.

\section{RESULTADOS}

Em tôdas as amostras de LCR analisadas o número de células era normal e as reações imunológicas foram negativas.

São apresentados, na tabela 1 , os resultados referentes à avaliação semiquantitativa do exame neurológico e ao estudo das proteinas totais e fraçōes do LCR e do sôro.

Proteinograma do $L C R$ - Em relação aos valôres normais "17 para a proteinorraquia total em nível lombar (média $24,0 \mathrm{mg} / 100 \mathrm{ml} \pm 6,3$ ) verifica-se que houve aumento da concentração protêica total do LCR em 7 dos 22 casos estudados. Os aumentos encontrados foram discretos, sendo de $53 \mathrm{mg} / 100 \mathrm{ml}$ a maior cifra registrada. A diferença entre a média normal e a encontrada em nossos casos de ND $(35,3 \mathrm{mg} / 100 \mathrm{ml} \pm 8,9)$ foi altamente significativa $(t=7,92 ; P<0,001)$.

$\mathrm{Em}$ todos os casos de ND o perfil eletroforético das proteinas do LCR era do tipo encontrado no LCR em condiçōes normais; assim, a albumina representou, em todos, a maior das frações; entre as globulinas predominavam as do grupo $\beta$.

Pequenas alterações quanto ao teor de cada uma das frações foram registradas: em 2 casos a pré-albumina não foi encontrada; havia diminuição da percentagem de albumina em 2 pacientes (casos 5 e 6) e aumento em 3 ( $\operatorname{casos} 15,20$ e 21). O teor relativo da globulina $\alpha_{1}$ estava aumentado em um paciente (caso 17), o das globulinas $\beta$ estava diminuido $\mathrm{em}$ um (caso 15) e o de globulina $\gamma$, aumentado em 3 casos (5, 6 e 9). Por serem discretas, essas alterações não provocaram modificações do conjunto do perfil єletroforético das proteinas do LCR. Igualmente, o perfil não sofreu alterações em função da intensidade da proteinorraquia total, conforme se verifica agrupando os resultados segundo a proteinorraquia estivesse entre 21 e 30 , entre 31 e 40 e entre 41 e $53 \mathrm{mg} / 100 \mathrm{ml}$ (tabela 2).

Proteinograma do sôro - Para 20 pessoas sadias englobadas na análise feita em publicação anterior ${ }^{16}$ a média da proteinemia total correspondeu a $7,29 \mathrm{~g} / 100$ $\mathrm{ml} \pm 0,66$. A proteinemia total nos casos de ND estudados é representada pela média de $7,73 \mathrm{~g} / 100 \mathrm{ml} \pm 0,41$. A diferença entre essas médias é significativa ( $t=2,44 ; P \simeq 0,02)$.

A separação das frações protêicas do sôro por eletroforese em papel permitiu estabelecer, para o grupo de pessoas sadias referido, os valôres médios seguintes: $3,99 \mathrm{~g} / 100 \mathrm{ml}$ para a albumina e, para a globulina $\alpha_{1} 0,29$, para $\alpha_{2} 0,67$, para $\beta 0,97$ e para $\gamma$ 1,36. Os valôres médios encontrados para o sôro dos pacientes com ND

* Bio-thesiometer, Bio-Medical Instruments Co., Newbury, Ohio, E.U.A. 


\begin{tabular}{c|c|c|c|c|c|c|c}
\hline $\begin{array}{c}\text { Proteinas } \\
\text { totais }\end{array}$ & $n$ & $\begin{array}{c}\text { Pré- } \\
\text { albumina }\end{array}$ & Albumina & \multicolumn{5}{|c}{ Globulinas } \\
\cline { 3 - 7 } $21-30$ & 9 & 2,9 & 53,1 & 4,6 & 7,1 & 19,6 & 10,5 \\
$31-40$ & 6 & 1,2 & 55,3 & 4,2 & 7,3 & 21,7 & 10,2 \\
$41-50$ & 7 & 2,4 & 52,7 & 5,9 & 7,6 & 21,1 & 10,2 \\
\hline
\end{tabular}

Tabela 2 - Percentuais médios representativos das frações protêicas do LCR, agrupando os pacientes estudados segundo a taxa de proteinas totais $(\mathrm{mg} / 100 \mathrm{ml})$ do LCR. Legenda: $n$, número de casos.

foram: para a albumina $3,65 \mathrm{~g} / 100 \mathrm{ml}$ e, para a globulina $\alpha_{1} 0,35$, para $\alpha_{2} 0,83$, para $\beta 1,15$ e para y 1,76. A relação entre os valôres médios referentes aos pacientes com ND e às pessoas sadias é l'epresentada por valôres superiores à unidade para as globulinas $\left(\alpha_{1} 1,21 ; \alpha_{2} 1,24 ; \beta 1,15 ; \gamma 1,29\right)$, enquanto para a albumina essa relaçāo corresponde a 0,91 . Estes dados mostram que o aumento da proteinemia total verificado em nossos casos era devido à maior concentração das globulinas no sôro. A freqüência em que ocorreram êsses aumentos é ilustrada no gráfico 1.

\begin{tabular}{|c|c|c|c|c|c|}
\hline \multirow{2}{*}{ Frações } & \multirow{2}{*}{ Albumina } & \multicolumn{4}{|c|}{ Globulinas } \\
\hline & & $\alpha_{1}$ & $\alpha_{2}$ & $\beta$ & $\gamma$ \\
\hline \multirow{2}{*}{ Média normal } & 000000 & $\begin{array}{l}000000 \\
000000\end{array}$ & $\begin{array}{l}0 \\
\text { oc0000 } \\
\text { o00000 }\end{array}$ & $\begin{array}{l}\text { o } \\
\text { oooooo } \\
\text { oooooo }\end{array}$ & $\begin{array}{l}\text { oooo } \\
\text { oooooo } \\
\text { oooooo }\end{array}$ \\
\hline & $\begin{array}{l}\text { odooooo } \\
\text { ocooo }\end{array}$ & 00000 & 0000 & 0000 & o \\
\hline
\end{tabular}

Gráfico 1 - Distribuição em relaçio ao normal das concentraçōes das frações protêicas do sôro, referentes aos 17 casos em que foram estudadas.

Correlação entre a concentraçĩo protêica total do LCR e do sôro - A exploração da correlação entre as taxas de proteínas totais no LCR e no sôro para os 17 casos em que ambas foram estudadas mostrou-se não significativa $(r=+0,054)$.

Relação entre o perfil eletroforético do LCR e do sôro - Em condiçôes normais, a relação entre o perfil protêico do LCR e do sôro respectivo é definida pela unidade para a albumina e para as globulinas $\alpha$ e é representada pelos valôres médios de 1,7 e de 0,5 para as globulinas $\beta$ e $\gamma$, respectivamente. Nos casos de ND estudados foi verificado comportamento diferente. A percentagem de albumina do LCR, na maioria das vêzes, era maior que no sangue, determinando aumento da relação LCR/sôro. Tendência inversa foi verificada em relação ao normal quanto 
às globulinas; na maioria dos casos a relação estava diminuida, por aumento da respectiva percentagem no sôro (gráfico 2).

\begin{tabular}{|c|c|c|c|c|}
\hline \multirow{2}{*}{$\begin{array}{c}\text { Relaç̄oo } \\
\text { LCR/sôro }\end{array}$} & \multirow{2}{*}{ Albumina } & \multicolumn{3}{|c|}{ Globulinas } \\
\hline & & $\alpha$ & $\beta$ & $\gamma$ \\
\hline \multirow{2}{*}{ Média normal } & $\begin{array}{l}\text { ooo } \\
\text { oooooo } \\
\text { oooooo }\end{array}$ & oo & ooo & 00000 \\
\hline & oo & $\begin{array}{l}\text { o00000 } \\
\text { oo0ooo } \\
\text { ooo }\end{array}$ & $\begin{array}{l}\text { oooooo } \\
\text { o00000 } \\
\text { oo }\end{array}$ & $\begin{array}{l}000000 \\
000000\end{array}$ \\
\hline
\end{tabular}

Gráfico 2 - Relaç̃̃o LCR/sôro. Distribuição dos 17 casos em que o LCR e o sôro foram estudados em relação aos valôres médios normais.

Relaçio entre as concentrações protêicas do LCR $e$ a avaliação semiquantitativa da sintomatologia neurológica - No material estudado nāo foi demonstrada correlação estatisticamente significante entre os dados analisados (tabela 3). Entretanto, os valôres obtidos sugerem: correlação da proteinorraquia total com a sintomatologia; dentre as fraçoes protêicas, maior participação da globulina $\beta$ nessa correlação.

\begin{tabular}{|c|c|c|c|c|}
\hline Estati & isticas & \multirow{2}{*}{$r$} & \multirow{2}{*}{$t_{r}$} & \multirow{2}{*}{$P$} \\
\hline \multicolumn{2}{|l|}{$L C R$} & & & \\
\hline Proteinas & totais & $+0,292$ & 1,365 & 0,18 \\
\hline Albumina & & $+0,230$ & 1,055 & 0,30 \\
\hline Globulinas & $\alpha$ & $+0,297$ & 1,390 & 0,17 \\
\hline Globulinas & $\beta$ & $+0,350$ & 1,671 & $c, 11$ \\
\hline Globulinas & $\gamma$ & $+0,052$ & 0,232 & 0,80 \\
\hline
\end{tabular}

Tabela 3 - Correlaçâo entre a sintomatologia neurológica global e as proteinas do liquido cefalorraqueano.

\section{COMENTARIOS}

O estudo dos casos reunidos nesta publicação confirma que é comum ocorrer dissociação proteinocitológica no LCR de pacientes com neuropatia diabética. Assim, em 7 casos foi verificada hiperproteinorraquia; êsses casos representam $32 \%$ do total de pacientes estudados, freqüência pouco inferior à referida por Martin "1 em relação a seu material $(38,5 \%)$. Por outro lado, os dados encontrados confirmam que o aumento da concentração pro- 
têica do LCR na ND costuma ser discreto; a maior taxa encontrada foi de $53 \mathrm{mg} / 100 \mathrm{ml}$. Em seu conjunto, a proteinorraquia total dos casos estudados é representada pela média de $35,3 \mathrm{mg} / 100 \mathrm{ml} \pm 8,9$. A diferença entre êste valor e a média normal é altamente significativa.

$\mathrm{Na}$ neuropatia diabética o aumento da proteinorraquia total não se acompanha de alterações especiais das diversas fraçōes protêicas do LCR. Assim, o perfil eletroforético foi em todos os casos do tipo encontrado para - LCR normal. Em média, a participação das frações protêicas do LCR no perfil eletroforético se mostrou pràticamente a mesma tanto entre casos com proteinorraquia total normal como entre aquêles em que ela estava aumentada.

As ocasionais alterações referidas para o teor de frações protêicas do LCR foram discretas, não determinando alterações do perfil eletroforético. Hammack e col. ${ }^{6}$ referem achados semelhantes em pacientes com neuropatia diabética; contudo, não apresentaram dados numéricos que permitam avaliar a freqüência, a natureza e a intensidade do aumento de globulina $\gamma$ a que acenam. Quando êste ocorreu, em nossa série de casos, foi discreto.

Não foi estatisticamente significativa a correlação entre a concentração prctêica do LCR e do sôro. Esse dado confirma a conclusão de Madonick e col. ${ }^{10}$ sôbre o assunto. Igualmente não foi encontrada relação entre os perfis eletroforéticos das proteínas do LCR e do sôro. As alterações verificadas em relação a êste último não transpareceram no LCR, do que resultaram alteraçōes das relações normalmente observadas entre os teores das frações protêicas no LCR e no sôro.

A interdependência da sintomatologia neurológica e da concentração protêica do LCR $t \in m$ sido explorada por vários autores. Martin ${ }^{11}$ e Plum ${ }^{13}$ não observaram correlação entre ambas. Canelas e col. ${ }^{4}$, para 28 diabéticos, verificaram que a média da proteinorraquia do grupo com sintomatologia neurológica mais grave era significativamente maior que a do grupo com sinais de comprometimento moderado do sistema nervoso. Posteriormente ${ }^{3}$, em 40 pacientes com diabetes mellitus, a correlação entre a sintomatologia neurológica global, avaliada semiquantitativamente, e a proteinorraquia total mostrou-se significativa. Adotando o mesmo método de pesquisa para a presente série de casos de ND, não foi possível confirmar a existência de correlação significativa entre a concentração protêica total do LCR ou de cada uma das respectivas frações e o resultado da avaliação semiquantitativa de sintomatologia neurológica. Êste achado pode resultar do fato de o número de casos analisados nesta série ser menor. Pode resultar também da existência de correlação entre os dados referentes à proteinorraquia e um outro fator. A êste outro fator é que na realidade estaria correlacionada também a sintomatologia neurológica. Por coincidência, nessas condições, seria possível demonstrar correlação entre a sintomatologia e a proteinorraquia total em dada amostragem. A favor desta última hipótese deve ser lembrado que o valor da correlação encontrado para a série de casos anteriormente analisada ${ }^{3}$, embora estatìsticamente significativo, era baixo $(\mathrm{r}=+0,462)$. 
Kutt e col. ${ }^{8}$, estudando por meio de eletroforese em gel de amido (técnica de Smithies) as proteínas do LCR em 78 pacientes diabéticos, verificaram aumento da globulina $\alpha_{2}$-s ("slow alpha-2 globulin"). Esta globulina é um dos componentes das globulinas do grupo $\alpha_{2}$ e não se isola das demais por eletroforese em papel. Sua presença no LCR normal é demonstrável, mas só é evidente quando ocorrem distúrbios da barreira hemoliquórica. Os autores referidos verificaram que o aumento dessa subfração no LCR foi mais evidente entre os pacientes com lesões vasculares mais severas, não guardando correlação com a hiperproteinorraquia e a intensidade ou o tipo de lesão do sistema nervoso.

Os dados referentes aos casos de neuropatia diabética aqui estudados encaminham no mesmo sentido as conclusōes. Conforme foi analisado nos parágrafos anteriores, a hiperproteinorraquia não mostrou dependência direta com as alterações do proteinograma do sôro e com a sintomatologia neurológica. Ela pode, entretanto, estar na dependência de alterações vasculares. Estas acarretariam um aumento da passagem de proteínas do sangue para o LCR, inespecífica em relação a cada fração protêica. Como resultado, haveria aumento da concentração protêica total do LCR sem que se produzissem alteraçōes do perfil eletroforético, conforme se verificou na série de casos estudados. Lesões mais acentuadas poderiam acarretar distúrbios maiores na passagem de uma ou outra fração protêica, sem alterar sobremodo o perfil eletroforético. Êstes distúrbios referentes a frações isoladas apresentariam aspectos peculiares a cada caso; entre êles se encontram as alterações citadas da literatura e de alguns dos casos desta série.

\section{RESUMO}

Tendo como objetivo analisar a hiperproteinorraquia que ocorre na neuropatia diabética, foi estudado o proteinograma do LCR de 22 pacientes portadores dessa afecção. Para fins comparativos, em 17 dêles foi feito na mesma ocasião o estudo do proteinograma do sôro. A sintomatologia neurológica foi avaliada de modo semiquantitativo.

Foi verificado aumento discreto da concentração protêica total do LCR em 7 casos (32\%). O perfil eletroforético (eletroforese em papel) das proteinas foi do tipo encontrado no LCR normal, em todos os casos. Discretas alterações quanto ao teor de uma ou outra fração foram registradas. O perfil protêico não apresentava particularidades relacionadas ao fato de ser normal ou aumentada a concentração protêica total do LCR.

A relação entre a percentagem no LCR e no sôro de cada uma das frações mostrou alteraçōes do balanço protêico entre LCR e sôro. As alterações eram devidas a modificações globulínicas do proteinograma do sôro. Não foi encontrada correlação significativa entre a concentração protêica do LCR e a do sôro.

O resultado da avaliação semiquantitativa da sintomatologia neurológica de cada caso foi correlacionado à concentração protêica total e de cada fração protêica do LCR. Não foi demonstrada correlação estatisticamente 
significante entre os dados analisados. Entretanto, os valôres obtidos sugerem: correlação da proteinorraquia total com a sintomatologia neurológica; dentre as frações protêicas, maior participação da globulina $\beta$ nessa correlação.

Em vista dos resultados obtidos para os casos estudados, os autores consideram que o aumento da proteinorraquia total na neuropatia diabética não pode ser pôsto na dependência de alterações peculiares a uma ou outra fração protêica do LCR. Igualmente, não depende de modificaçōes do proteinograma do sôro e não pode ser explicado em funçāo direta da intensidade do quadro neurológico.

É discutida a possibilidade de estar a hiperproteinorraquia relacionada às alterações da barreira hemoliquórica, secundárias às lesões vasculares que acompanham o diabetes mellitus.

\section{SUMMARY}

Cerebrospinal fluid proteins and their electrophoretic pattern in diabetic neuropathy.

The present study was carried out in order to investigate the nature of the increase in the cerebrospinal fluid (CSF) protein content described in diabetic neuropathy. The CSF proteins were studied in 22 patients with clinical signs of diabetic neuropathy.

The total protein content and the electrophoretic pattern (paper electrophoresis) of the proteins were studied in one CSF sample of each patient. The CSF sample was collected through lumbar puncture. For comparative purposes, the total protein content and the electrophoretic pattern of the blood serum proteins were determined in 17 patients. For the same purpose the impairment of the nervous system was evaluated in a semi-quantitative way.

The CSF protein concentration was increased in 7 cases $(32 \%)$. The increases were slight. The electrophoretic patterns were found to be similar to those found in normal conditions. The relative values found for each of the protein fractions were increased in some instances. Such increases were slight and did not change the protein pattern of the CSF. Among these changes, that regarding the $\gamma$-globulin was observed in 3 cases.

The CSF protein pattern did not show changes related to the total protein content of the sample. Changes in the serum protein pattern did not induce changes in the CSF protein pattern. The correlation between the total protein content of CSF and serum was not statistically significant.

In the cases studied no statistically significant correlation between the degree of neurological involvement and the CSF proteins was found. However, the data suggest a trend to correlation between the neurological picture and the total protein content of the CSF, particularly with $\beta$-globulin. 
The results show that the increase in the total protein content of the $\mathrm{CSF}$ in diabetic neuropathy is not related to changes regarding one or more of the protein fractions of CSF. It is not dependent also on the protein concentration in the blood serum and/or the changes found in its protein pattern. The degree of the nervous impairment in itself cannot be directly related to the increase in the CSF proteins.

The importance of damage in the blood-CSF barrier is pointed out by data of the literature concerning the protein fractions in diabetic patients. Such damage cannot be excluded in the discussion of the results found. Its presence would enhance the passage of proteins to the CSF, thus resulting an increase in the total protein content. Changes in the protein pattern in such conditions are absent or slight, as it was found in the cases studied.

\section{REFERENCIAS}

1. ALEXANDER, L. - New concept of critical steps in the course of chronic debilitating neurologic disease in evaluation of therapeutic response. Arch. Neurol. a. Psychiat. (Chicago) 66:253-271, 1951. 2. CANELAS, H. M. - Sensibilidade vibratória: valor semiótico em algumas afecçoes do sistema nervoso. Arq. Neuro-psiquiat. (São Paulo) 16:275-352, 1958. 3. CANELAS, H. M. - Neuropatia diabética. Rev. Paul. Med., 62:29-42, 1963. 4. CANELAS, H. M.; EPPS, D. R.; FERRAZ, E. C. F.; TEIXEIRA-PINTO, J. - Neuropatia diabética: considerações sôbre 33 casos. Rev. Paul. Med., 49:169-190, 1956. 5. CANELAS, H. M.; JAMRA, M. A. - Estudo comparativo dos efeitos hematológicos e neurológicos do extrato hepático, ácido fólico e vitamina $B_{12}$ no tratamento da anemia perniciosa de Addison-Biermer. Arq. Neuropsiquiat. (São Paulo) 11:229-246, 1953. 6. HAMMACK, W. R.; STARNES, W. R.; HILL Jr., S. R. - Studies on the spinal fluid and serum protein electrophoretic pattern in patients with diabetes mellitus. J. clin. Invest., 36:897, 1957. 7. KOLMER, J. A.; SPAULDING, E. H.; ROBINSON, H. W. - Approved Laboratory Technic, 5* ed., Appleton-Century-Crofts Inc., New York, 1951. 8. KUTT, H.; HURWITZ, L. J.; GINSBURG, S. M.; MCDOWELL, F. - Cerebrospinal fluid protein in diabetes mellitus. Arch. Neurol. (Chicago) 4:31-36, 1961. 9. LANGE, O. - O Liquido Céfalo-raquidiano em Clínica. Cia. Melhoramentos de São Paulo, São Paulo, 1938. 10. MADONICK, M. J.; MARGOLIS, J. - Protein content of spinal fluid in diabetes mellitus. Arch. Neurol. a. Psychiat. (Chicago) 68:641-644, 1952. 11. MARTIN, M. M. - Diabetic neuropathy: a clinical study of 150 cases. Brain 76:594-624, 1953. 12. MIRSKY, I. A.; FUTTERMAN, P.; BROH-KAHN, R. H. - The quantitative measurement of vibratory perception in subjects with and without diabetes mellitus. J. Lab. clin. Med., 41: 221-235, 1953. 13. PLUM, F. - The neurologic complications of diabetes mellitus. In Williams, R. H. - Diabetes. P. Hoeber, New York, 1960, págs. 602-622. 14. RUNDLES, R. W. - Diabetic neuropathy: general review with report of 125 cases. Medicine 24:111-160, 1945. 15. SPINA-FRANÇA, A. - Eletroforese em papel das proteinas do líquido cefalorraquidiano. III: Técnicạ. Arq. Neuro-psiquiat. (São Paulo) 16:236-242, 1958. 16. SPINA-FRANÇA, A. - Eletroforese em papel das proteinas do liquido cefalorraquidiano. IV: Valóres normais. Arq. Neuro-psiquiat. (São Paulo) 18:19-28, 1960. 17. SPINA-FRANÇA, A.; AMAR, I. - Valôres normais da concentração protêica do liquido cefalorraquidiano: variações ligadas ao local da colheita da amostra. Arq. Neuro-psiquiat. (São Paulo) 19:220-225, 1961.

Clinica Neurológica - Faculdade de Medicina da USP - Caixa Postal 3461 São Paulo, SP - Brasil. 